
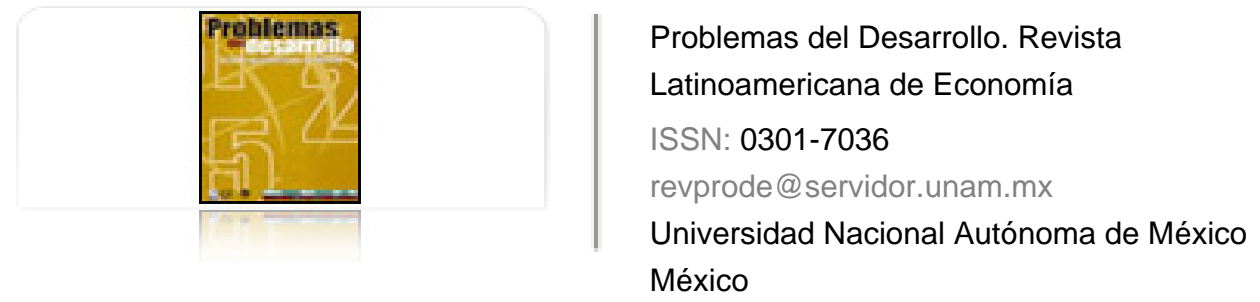

Suárez Estrada, Marcela

El papel de las instituciones en el cambio económico de México

Problemas del Desarrollo. Revista Latinoamericana de Economía, vol. 39, núm. 154, julio-septiembre, 2008, pp. 37-60

Universidad Nacional Autónoma de México

Distrito Federal, México

Disponible en: http://www.redalyc.org/articulo.oa?id=11820139003

Cómo citar el artículo

- Número completo

- Más información del artículo

Página de la revista en redalyc.org

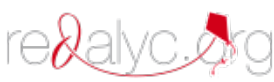

Sistema de Información Científica

Red de Revistas Científicas de América Latina, el Caribe, España y Portugal Proyecto académico sin fines de lucro, desarrollado bajo la iniciativa de acceso abierto 


\title{
EL PAPEL DE LAS INSTITUCIONES EN EL CAMBIO ECONÓMICO DE MÉXICO
}

\author{
Marcela Suárez Estrada* \\ La separación institucional de la política y la economía, \\ que resultaba mortalmente peligrosa para la sustancia \\ de la sociedad, producía casi automáticamente \\ la libertad a costa de la justicia y la seguridad. \\ Karl Polanyi
}

Fecha de recepción: 29 de febrero de 2008. Fecha de aceptación: 14 de julio de 2008.

\section{Resumen}

La creación y el cambio institucional que dio paso a la apertura comercial en México tuvo dos fuerzas: por un lado influyó positivamente en cuanto a mejoras en la eficiencia, transparencia, organización, información y coordinación económica entre los agentes, debido a la creación y reforma de una serie de instituciones formales (leyes, códigos, normas y reformas constitucionales); pero por otra parte el cambio económico no fue apoyado por políticas públicas que ayudaran a la planta productiva a enfrentar una profunda transformación, como pueden ser soportes financieros, de reconversión industrial, infraestructura y apoyos productivos a empresas, por lo que el desempeño económico, después de la apertura comercial, contribuyó a la configuración de un nuevo patrón de comercio exterior con características particulares como la concentración de las actividades comerciales en regiones, empresas, sectores y países destino.

Palabras clave: instituciones, cambio económico, cambio institucional y apertura comercial en México.

* Realiza estudios de doctorado en la Universidad Autónoma de Madrid. Correo electrónico: marcela_srz@yahoo.com.

Con el apoyo del Programa de Becas de Alto Nivel de la Unión Europea para América Latina (Programa ALBAN), beca núm. E05D058291MX, y el Consejo Nacional de Ciencia y Tecnología (CONACYT), núm. 196650. 
MARCELA SUÁREZ ESTRADA

Abstract

The institutional creation and change that gave rise to the trade opening in Mexico was driven by two factors: on the one hand, it was influenced positively by the improvements in efficiency, transparency, organization, information and economic coordination between economic agents, due to the creation and reform of a series of formal institutions (legal, code of practice, regulatory and constitutional norms and reforms); on the other hand, the economic change was not supported by public policies that helped the production facilities to deal with such a profound transformation, such as financial support, industrial conversion, infrastructure and productive supports to companies. Thus economic performance after the trade opening contributed to the configuration of a new pattern of foreign trade with particular characteristics such as the concentration of trading activities in regions, companies, sectors and countries of destination.

Key words: institutions, economic change, institutional change, trade opening in Mexico.

\section{Résumé}

Le changement institutionnel qui a permis l'ouverture commerciale au Mexique a eu deux points forts: d'une part, il a influencé positivement l'économie en cela qu'il a amené des améliorations en matière d'efficacité, de transparence, organisation, information et coordination entre les différents agents grâce à la création et réforme d'une série d'institutions formelles (lois, codes, normes et réformes constitutionnels); d'autre part le changement économique n'a pas été soutenu par des politiques publiques qui soient venues aider le secteur productif à affronter une profonde transformation, tels que appuis financiers, de reconversion industrielle, infrastructure et aides à la production, et l'activité économique, après l'ouverture commerciale, a donc contribué à configurer un nouveau panorama du commerce extérieur avec des caractéristiques particulières comme la concentration des activités commerciales dans des régions, entreprises, secteurs et pays de destination spécifiques.

Mots clés: institutions, changement économique, changement institutionnel et ouverture comerciale au Mexique.

\section{Resumo}

A criação e a mudança institucional que se deu na apertura comercial no México tiveram duas forças: por um lado influiu positivamente quanto a melhoras na eficiência, transparência, organização, informação e coordenação econômica entre os agentes, devido à criação e reforma de uma série de instituições formais (leis, códigos, normas e reformas constitucionais); mas por outra parte a mudança econômica não foi apoiada por políticas públicas que ajudaram a planta produtiva a enfrentar uma profunda transformação, como podem ser suportes financeiros, de reconversão industrial, infraestrutura e apoios produtivos a empresas, pelo que o desempenho econômico, depois da apertura comercial, contribuiu a configuração de um novo padrão de comércio exterior com características particulares como a concentração das atividades comerciais em regiões, empresas, setores e paises destino.

Palavras chave: Instituições, mudança econômica, mudança institucional e apertura comercial no México.

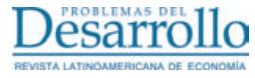

Vol. 39, núm. 154, julio-septiembre / 2008 
Introducción

1 proceso de internacionalización de la economía mexicana ha sido un fenó-

meno de gran trascendencia: de ser una economía de las más cerradas, pasó a

ser una de las más abiertas, lo que convirtió a México en uno de los principales países exportadores e importadores del sistema internacional; este proceso significó un cambio productivo estructural con importantes implicaciones en la organización económica, política y social, así como en el desempeño económico.

Antes de la apertura comercial México experimentó un periodo sustitutivo de importaciones caracterizado por una fuerte regulación de la economía por parte del Estado, mediante diversas instituciones, entre las que destacan excesiva protección comercial, control de flujos de inversión extranjera directa (IED), nacionalización de empresas y regulación de la economía en varios ámbitos.

En la década de los ochenta la apertura comercial resultó de gran trascendencia para la economía mexicana, al desmantelar el esquema proteccionista de los 40 años anteriores. Las principales transformaciones en este ámbito estuvieron encaminadas a abrir la economía a los mercados internacionales y liberalizar diversas actividades productivas que por muchos años habían estado restringidas a las autoridades o al capital mexicano, lo que tuvo múltiples y heterogéneos efectos en la economía: por un lado, se llevó a cabo una mayor dinámica económicas y, por otro, se tendió a la concentración de actividades y beneficios económicos.

No se podría entender el proceso de apertura comercial mexicano sin dimensionar el cambio y creación institucional que se llevó a cabo y, sobre todo, en la forma que influyó en el comercio exterior. Partimos de la base de que el cambio institucional del proceso de apertura comercial fue trascendental: por una parte impulsó una profunda transformación en la estructura y dinámica económicas y, por otra, dejó ver las deficiencias productivas de la economía acumuladas a lo largo del tiempo.

El objetivo general de este artículo es identificar y establecer las principales características de las instituciones asociadas al proceso de apertura comercial y dar elementos que muestren la asociación con el comportamiento del comercio exterior mexicano. Debido a la amplitud y complejidad del tema en cuestión, este trabajo profundizará en el papel de las instituciones formales (leyes y reglas escritas) y se dejará para futuras investigaciones el desempeño de las informales. Se parte de la hipótesis de que la creación y el cambio institucional que dio paso a la apertura comercial tuvo dos fuerzas: por un lado, influyó positivamente en cuanto a mejoras en la eficiencia, transparencia, mejor organización, información y coordinación económica entre los agentes debido a la creación de una serie de instituciones formales (leyes, códigos,

Vol. 39, núm. 154, julio-septiembre / 2008

Desarrollo 
normas y reformas constitucionales) que dirigieron el proceso de apertura de la economía; sin embargo, la creación y reforma institucional no fue apoyada por otro tipo de innovaciones institucionales y de política que ayudaran a la economía a enfrentar una profunda transformación económica, como pueden ser soportes relativos a financiamiento, infraestructura y apoyos productivos a empresas, por lo que el desempeño económico, después de la apertura comercial, contribuyó a la configuración de un nuevo patrón de comercio exterior con características particulares como la concentración de las actividades comerciales en regiones, empresas, sectores y países destino. En el proceso institucional de la apertura comercial se observa un gran cambio en la estructura económica con un débil papel del Estado en cuanto a la aplicación de una política industrial que lo acompañara, por lo que áreas importantes de la economía se dejaron en manos del libre mercado sin tomar en cuenta las condiciones y necesidades particulares de las empresas para participar en los mercados internacionales.

Los cambios institucionales previstos en este trabajo se refieren a cambios formales, sobre todo en cuanto a leyes, códigos y normas escritas en el proceso de apertura comercial. En la primera parte del artículo se destacan algunas aportaciones teóricoconceptuales de la teoría institucional en la economía; en la segunda se aborda la creación y desarrollo institucional formal en el proceso de apertura comercial en México; en la tercera se examina el desempeño económico después de la apertura comercial y, por último, se presentan los comentarios finales.

\section{Instituciones, conceptos y aportaciones teóricas}

La evolución de la teoría institucional ha tenido diferentes enfoques y aproximaciones. Respecto a las ciencias sociales, han estudiado las instituciones y su importancia para las estructuras económicas, políticas y sociales, situación que ha hecho que la teoría institucional no se haya desarrollado como un único cuerpo homogéneo, sino como un enfoque multidisciplinario, interdependiente y con variaciones en cuanto al concepto de instituciones, según la escuela en cuestión. En la actualidad hay varios enfoques sobre la teoría institucional, y es evidente la relevancia del estudio de las instituciones en el campo económico y sus interrelaciones con los campos político, sociológico, psicológico y hasta antropológico.

Es conveniente resaltar que no existe una definición unánime y homogénea de lo que significa la palabra institución, ya que puede abordarse desde diferentes niveles de análisis en las ciencias sociales y, en particular, en la teoría económica. Se pueden destacar cuatro ejes que engloban las principales aportaciones teóricoconceptuales de las instituciones: 1) el de análisis y origen de las instituciones, con

\section{DeSTarrollo}

Vol. 39, núm. 154, julio-septiembre / 2008 
énfasis en el proceso cognitivo, relacionado con todo el proceso mental y sensorial interno en los humanos, el cual puede incluir los pensamientos, sensaciones y percepciones que son determinantes para explicar por qué un ser humano actúa de tal o cual forma (Hayek: 1990; 2004; Loasby: 1999, Hodgson: 1988); 2) el cultural, que se refiere a los hábitos, patrones de comportamiento, rutinas, reglas y convenciones que se transmiten de generación en generación y que prevalecen a lo largo del tiempo, al delinear la acción de los individuos y establecer una ruta para su interacción; 3) el organizativo, enfocado a la interacción de unos individuos con otros, lo que da como resultado una dinámica propia (Simon: 1991, Nelson y Winter: 1982); y 4) el formal, que tiene que ver con las instituciones en cuerpos jurídicos formales como leyes, códigos, normas, entre otros (Coase: 1937; North: 1993; 2004; Williamson: 1998). Estos cuatro niveles interactúan entre sí y dan como resultado la estructura institucional. El presente artículo pondrá más énfasis en el nivel formal de las instituciones.

El enfoque de costos de transacción ve a las instituciones como aquellas reglas del juego en una sociedad, limitaciones que dan forma a la interacción humana y que constituyen la estructura de incentivos en el intercambio político, económico y social. Dicho enfoque hace una clara distinción entre aquellas normas formales (leyes, reglas, normas, códigos, etcétera) e informales (tradiciones, patrones de cultura, normas de comportamiento) (North:1993) y destaca su importancia en cuanto a la creación de incentivos como el respeto a los derechos de propiedad y reducción de costos de transacción (Coase:1937 y Williamson:1998).

Un concepto más amplio de institución lo brinda Hodgson (1988) al establecer que una institución es una organización social en donde mediante la tradición, la costumbre y el cuerpo legal se tiende a crear patrones de comportamiento durables y rutinarios; señala que las instituciones son sistemas establecidos y generales de reglas sociales que estructuran la interacción social.

Las instituciones formales como reglas escritas son importantes para el proceso económico debido a que pueden penalizar, prohibir, obligar, facilitar, informar, definir, diseñar, constituir, distribuir, identificar, requerir, guiar, esforzar, permitir y comandar la acción colectiva (Vanberg: 1999). Pueden funcionar si las reglas, procedimientos, incentivos y sanciones que establecen son integrados en convenciones que guían el comportamiento de los humanos para cumplirlas.

Sin embargo, debe destacarse que el surgimiento y evolución de las instituciones no es siempre positiva para la economía, ya que pueden surgir instituciones específicas como la informalidad, la migración y la delincuencia como mecanismos de 
adaptación ante la complejidad e incertidumbre de una nueva realidad que resulta incompatible con las condiciones y patrones de conducta de los agentes.

En principio, hay instituciones formales que son reconocidas y autorizadas por una autoridad como el Estado, pero son organizadas y mantienen una estrecha relación con la acción social, ello es porque las actividades económicas están incrustadas en estructuras sociopolíticas que determinan su papel y funcionamiento en asuntos sociales y políticos, y a la vez éstos influyen en la actividad económica y determinan los límites dentro de los cuales el mercado funciona (Gilpin:2001). De ahí que algunos autores, como Ha Joon Chang (1996; 2004), destaquen el papel del Estado en el cambio económico y sostengan que es un mito el que para alcanzar una mayor eficiencia en el mercado, el Estado deba mantener un papel limitado en la economía.

El Estado puede fungir como un actor fundamental para reducir la incertidumbre inherente al cambio económico, para coordinar nuevos arreglos y darle sustento a cambios institucionales con políticas específicas; también tiene facultad para legalizar o cuando menos dar apoyo implícito a los nuevos derechos de propiedad y a las nuevas relaciones de poder, tanto en el ámbito de la sociedad como en el terreno empresarial; con ello se otorga realidad institucional a la nueva estructura de coordinación. Así podemos señalar que el Estado y el mercado se complementan por medio de interrelaciones entre una matriz de instituciones y convenciones (Burlamaqui et al.:2000).

Después de conocer los enfoques anteriores, una cuestión que cobra vital relevancia es el cambio institucional como resultado de la interacción de un conjunto de factores en múltiples niveles, entre los que sobresalen: 1) por evolución, 2) por accidente y 3) por intervención intencionada (Goodin:2003). Así, el cambio institucional se convierte en un proceso complejo que tiende a ser evolutivo, marcado por una secuencia gradual en el tiempo, altamente dependiente de la estructura institucional previa (path dependence) y condicionado por los cambios en el entorno y por las circunstancias de la dinámica social y política vigentes.

\section{La apertura comercial en México y sus aspectos institucionales}

Durante 40 años, desde principios de la década de los cuarenta y hasta principios de los ochenta, la economía mexicana se vio inmersa en el modelo sustitutivo de importaciones (en lo subsiguiente SI), que tenía como principal fin el desarrollo de la industria nacional por medio de la regulación de la actividad económica del Estado. Sus principales mecanismos fueron la protección comercial vía medidas arancelarias y no arancelarias, la regulación de la inversión extranjera (IE), un blindaje económico basado en el control de precios y la adopción de un sistema de tipo de cambio fijo.

\section{Désarrollo}

Vol. 39, núm. 154, julio-septiembre / 2008 
El Estado jugaba un papel determinante en el ámbito económico, ya que por medio del gasto público mantenía e impulsaba la actividad económica, lo que suponía una fuerte presión en las finanzas públicas y en la balanza de pagos, debido a los crecientes requerimientos de flujos externos para financiar el déficit, situación que sería más latente a partir de la segunda mitad de la década de los setenta (Cárdenas:1996).

En esta misma etapa, México presenta la primera crisis del modelo de crecimiento apoyado en el modelo SI, basado en una política fiscal expansiva que generaría un creciente déficit en el sector público, financiado sobre todo con aumento del circulante monetario y endeudamiento exterior, que en el corto plazo permitía impulsar la actividad económica pero con efectos inflacionarios posteriores.

Se desarrollaron diferentes políticas económicas que se englobaron en programas de estabilización para salir de la crisis; sin embargo, debido al periodo de creciente inestabilidad macroeconómica en el ámbito internacional, así como a la inercia de algunas variables internas, sería muy difícil configurar una estabilidad macroeconómica en los años siguientes; no sería hasta después de la crisis de 1987 cuando México consiguió estabilizar medianamente su economía, aunque en 1994 tuvo lugar una nueva crisis financiera.

A partir de la década de los ochenta la creación y el cambio institucional que se experimentó en México forman parte de un programa de reforma económica profunda que cambió las condiciones, la interacción y el patrón productivo y comercial de este país, teniendo como consecuencia un mayor desempeño productivo con alta concentración de beneficios. Una de las transformaciones más importantes fue la redefinición del papel del Estado en la economía por medio de un cambio institucional determinante (sobre todo en el ámbito formal y organizacional) que impulsó nuevas reglas del juego en la economía en cuanto a las formas de interacción entre los actores e instrumentos institucionales para la reconformación de un patrón industrial y económico. Ante este escenario, por un lado la creación institucional hubiera podido traer beneficios debido a una mayor eficiencia en la economía, pero, por otro, una transformación de tal envergadura en un periodo relativamente corto acrecentó la incertidumbre en los agentes, por lo que se hacía necesaria la presencia de políticas específicas que ayudaran a realizar un cambio económico tan importante (Clavijo:1994a; Dussel:1997).

El intenso cambio institucional en México respondió a los tres factores de creación y cambio institucional mencionados en el primer apartado de este artículo, a saber: por evolución, por intervención gubernamental y por accidente, examinados con mayor detenimiento a continuación: 
a) Evolución institucional. El proceso de apertura comercial respondió a la evolución creciente del comercio entre Estados Unidos (EU) y México debido a la cercanía geográfica, el intercambio de insumos y la mano de obra a precios bajos, aunado a una estrategia de integración comercial entre EU, Canadá y México. En el año 1993, antes de la entrada en vigor del Tratado de Libre Comercio de América del Norte (TLCAN), las exportaciones mexicanas se dirigían en $82.7 \%$ al mercado estadounidense; para 2006 la misma cifra aumentó a 85.5\%, lo que refleja que en cuanto al porcentaje total la concentración de las exportaciones casi no cambia, sino que con la puesta en marcha del tratado el volumen se expande de manera considerable.

b) Por intervención directa. En este nivel hay dos elementos importantes: el primero tiene que ver con el desgaste del modelo SI que implicó problemas macroeconómicos como desempleo, excesivo endeudamiento externo, crisis fiscal del Estado, inflación, caída de la inversión y devaluación que motivaron un cambio institucional intenso mediante la adopción de políticas específicas como privatización de empresas, desregulación de los mercados y apertura comercial por parte del gobierno, mientras que el segundo elemento tiene que ver con un cambio generacional e ideológico por parte de los políticos y funcionarios que acompañaron el diseño de los mecanismos institucionales de forma intencionada en el proceso de apertura comercial. Dicho cambio generacional se refiere a la llegada de presidentes y funcionarios más jóvenes impregnados de nuevas ideas que los políticos anteriores; también se experimentó un cambio en su formación como resultado de que cuadros de políticos y funcionarios que estudiaban tradicionalmente ciencia política, administración pública y derecho, quienes perdían cada vez más espacio y se formaban ahora en la carrera de economía.

En sentido operativo la apertura comercial fue impulsada desde las esferas del Poder Ejecutivo por un grupo de estudiantes que realizó postgrados en las prestigiosas universidades de EU como: Harvard y el Instituto Tecnológico de Massachussets (MIT), ${ }^{1}$ entre otras. En este grupo encontramos a los presidentes Miguel de la Madrid (1982-1988), Carlos Salinas de Gortari (1988-1994), Ernesto Zedillo (1994-2000), Luis Donaldo Colosio (candidato presidencial para las elecciones

1 Al respecto Roderic Camp (1990) da unas cifras interesantes al señalar que de 1940 a 1970, $58 \%$ de los políticos mexicanos habían estudiado ciencia política en la UNAM y sólo 13\% en EU. Mientras que para 1990 el 55\% había realizado estudios de postgrado en EU y eran economistas de profesión. Véase Roderic Camp, Los empresarios y la política económica en México, una visión contemporánea, México, FCE, 1990, p. 121. 
de 1994-2006, asesinado en marzo de 1994), y un grupo de funcionarios públicos que ocuparon la dirección de las principales dependencias en estos sexenios como: Jaime Serra Puche (Secretaría de Comercio y Fomento Industrial), Pedro Aspe (Secretaría de Hacienda y Crédito Público), José Ángel Gurría (Secretaría de Hacienda y Crédito Público y actual secretario general de la OCDE), Guillermo Ortiz (actual gobernador del Banco de México) y Francisco Gil Díaz (ex titular de la Secretaría de Hacienda).

$\mathrm{Al}$ regresar de sus estudios en el extranjero, este grupo en el poder ocupó puestos en altas esferas de organismos económicos e impulsaron desde diferentes estructuras del Poder Ejecutivo cambios y creaciones institucionales determinantes para el futuro del país. Como señala Ayala (1996), la reforma institucional fue decidida y puesta en marcha durante el gobierno de los presidentes Miguel de la Madrid, Carlos Salinas y Ernesto Zedillo desde arriba y con los mecanismos de poder tradicionales del sistema mexicano, lo que dificultó que las reformas llegaran efectivamente a contar con suficiente consenso y legitimidad por parte de institucionales informales en la sociedad.

c) Los factores externos que influyeron en la dinámica interna fueron las alzas de los precios del petróleo y las fluctuaciones económicas internacionales que repercutieron en la economía mexicana, como las subidas de los tipos de interés y restricciones de flujos externos de capital. Estos acontecimientos en una economía con debilidad en las variables macroeconómicas, dependiente de recursos económicos externos y con un déficit fiscal importante, la hacían vulnerable ante las subidas de las tasas de interés.

En general, fueron las condiciones del contexto económico internacional en la década de los noventa — como la importancia de flujos crecientes de comercio internacional, mayor competencia entre empresas, privatización, desregulación, deslocalización de actividades productivas y la creciente interdependencia económica en las naciones- las que suscitaron nuevos patrones de interacción en el sistema internacional. Un factor de presión para llevar a cabo cambios en la estructura interna institucional fue la integración de México a instituciones internacionales como la Organización Mundial de Comercio (OMC), antes Acuerdo General sobre Aranceles Aduaneros y Comercio (GATT, por sus siglas en inglés), el Fondo Monetario Internacional (FMI), el Banco Mundial (BM), la Organización para la Cooperación y del Desarrollo Económico (OCED) y los diversos tratados de libre comercio, en especial el TLCAN que es el que ha tenido mayor influencia en la estructura económica e institucional.

Vol. 39, núm. 154, julio-septiembre / 2008

Desarrorrollo 
Como lo señala la teoría institucional, la explicación del cambio en México en este ámbito no se puede abordar por uno solo de los factores señalados, sino que los tres (el evolutivo, el de intervención y el accidental) están conectados y su conjunción e interacción crearon una nueva dinámica que explica la transformación institucional en el país.

\section{La creación y la reforma institucional en el proceso de apertura comercial}

El proceso de apertura comercial en México fue un periodo de intensa creación y reforma institucional formal, que sería trascendental para el nuevo rumbo de la economía. Sin duda, a partir de 1982 en México se empezaría a constituir un nuevo tejido institucional, cuya evolución en el proceso de apertura comercial destacamos a continuación.

En el año 1982 el Programa Nacional de Fomento Industrial y de Comercio Exterior (PRONAFICE) 1984-1988 nace como una institución formal del gobierno que da dirección a la economía y parte de la base de que México requiere conformar un nuevo patrón de industrialización y comercio exterior, para ello se planea realizar un cambio estructural en la economía para que la industria y el comercio exterior constituyan el catalizador de un nuevo modelo de desarrollo, donde el Estado disminuirá de manera considerable su participación en la economía por medio de un programa de desregulación y privatización.

En cuanto a otras instituciones importantes, en 1981 se crea la Ley Aduanera y su organismo, la Administración General de Aduanas, que tiene como principal objetivo regular la entrada y salida de mercancías y de los medios que las transportan. Aunado a ello, se crea la Ley de Impuestos Generales de Importación y la Ley General de Impuestos de Exportación que definen las tarifas de aranceles para la entrada y salida de mercancías.

En 1985 se intenta la promoción de las exportaciones y se crean dos instituciones que serían determinantes para el futuro desempeño del sector externo y, en particular, para la industria manufacturera: el Decreto para el Fomento y Operación de la Industria Maquiladora de Exportación (IME) y el decreto por el que se establece el Programa de Importación Temporal para Producir Artículos de Exportación (PITEX), con el cual se permiten importaciones de materias primas temporales para la producción de artículos de exportación y operar con 100\% de capital extranjero. Estos programas iban de la mano con el objetivo de generar un cambio estructural, fomento a las exportaciones y relocalización industrial, para lo cual se creó otra importante institución en 1986, el Decreto de la Zona Fronteriza que tenía como objetivo impulsar la actividad de comercio exterior e inversiones en la región norte del país.

\section{DeSTarrollo}

Vol. 39, núm. 154, julio-septiembre / 2008 
Quizá la mayor relevancia de este periodo sea el cambio de dirección del modelo económico en México, donde se establece que la transformación estructural y la apertura comercial serán pilares del nuevo modelo de desarrollo y que se dará continuidad en sexenios posteriores; además el cambio en la intervención económica por parte del Estado también fue un hecho fundamental para la dinámica económica. Sin duda, el PRONAFICE sentó las bases de una nueva etapa en la historia económica de México y una reforma institucional profunda.

En el periodo del presidente Carlos Salinas se parte del Programa de Modernización Industrial y Comercio Exterior (PRONAMICE) 1990-1994, el cual establecía como principales fines promover el cambio estructural en la industria, fortalecer el mecanismo de la oferta y demanda en la asignación de los recursos, limitar la función del gobierno en el establecimiento de un ámbito favorable al desarrollo de las empresas con mayor estabilidad macroeconómica y eficiencia en el mercado de bienes y factores. A principios de la década de los noventa se realizan innovaciones institucionales determinantes para la eficiencia del mercado y para la liberalización comercial. En junio de 1993, el Congreso aprobó la nueva Ley de Comercio Exterior que buscaba asegurar que los productores internos enfrentaran una competencia justa en el exterior al penalizar prácticas desleales, facilitar el ajuste de los productores internos a la competencia extranjera con medidas temporales de salvaguardia, y promover las exportaciones. Esta ley crea su propio organismo, la Comisión de Comercio Exterior.

El 27 de diciembre de 1993 se publica en el Diario Oficial de la Federación (DOF) la Ley de Inversión Extranjera que abroga la Ley para Promover la Inversión Mexicana y Regular la Inversión Extranjera de 1973. Los cambios a las reglamentaciones sobre la IED contribuyeron a desmantelar el esquema proteccionista del periodo del modelo SI que consistía en reservar al Estado algunas actividades como petróleo y demás hidrocarburos, petroquímica básica, explotación de minerales radioactivos y generación de energía nuclear, minería, electricidad, ferrocarriles, comunicaciones telegráficas y radiotelegráficas; de igual forma, otras actividades como radio, televisión, transporte automotor urbano, transportes aéreos y marítimos, explotación forestal y distribución de gas que estaban reservadas de manera exclusiva para inversionistas mexicanos.

Por otro lado, en esta etapa México lleva a cabo un papel más activo en sus relaciones económicas con el exterior al participar en organismos internacionales, situación que también influiría en el cambio institucional; por ejemplo, en 1986 firma un convenio con la Asociación Latinoamericana de Integración (ALADI) y en

Vol. 39, núm. 154, julio-septiembre / 2008

Desarrollo 
1989 entra al Foro de Cooperación Económica del Pacífico Asiático (APEC, por sus siglas en inglés).

En materia de negociaciones internacionales, este periodo fue significativo debido a que se llevaron a cabo diversas negociaciones de tratados de libre comercio (TLC). En la primera mitad de la década de los noventa se suscribieron acuerdos con varios países, el primero de ellos con Chile en 1991; después el TLCAN, de mayor trascendencia por el volumen de comercio que se desarrolla con Canadá y Estados Unidos, que entró en vigor en 1994; en 1995 se firma el TLC del Grupo de los Tres, que lo conformaban Colombia, México y Venezuela, ${ }^{2}$ así como el firmado ese mismo año con Costa Rica.

A partir de la segunda mitad de la década de los noventa, México profundizó la firma de TLC al celebrar acuerdos con Bolivia (1995), Nicaragua (1998), la Unión Europea (2000), Israel (2000), Honduras, El Salvador y Guatemala (2001). Recientemente concluyeron las negociaciones para firmar un TLC con Uruguay y un Acuerdo de Asociación Económica (AAE) con Japón. Además, México ha negociado una gama de Acuerdos de Complementación Económica (ACE) y de Acuerdos para la Promoción y la Protección Recíproca de las Inversiones (APPRI) con diferentes países, sobre todo aquéllos con los que no se tienen tratados de libre comercio.

Es importante destacar que la mayor participación de México en organismos internacionales, el TLCAN y el proceso de apertura comercial en sí mismo fueron elementos que presionaron de manera profunda el cambio institucional para que existiera un mejor ambiente para los negocios mediante la creación de instituciones, como la Ley Federal de Competencia y la creación de la Comisión Federal de Competencia, con el objetivo de evitar prácticas monopólicas que lesionaran el sistema de competencia.

De igual forma, se fortaleció la protección de los derechos de propiedad con la reforma a la Ley de Fomento y Protección de la Propiedad Industrial y la creación del Instituto Mexicano de la Propiedad Industrial, dedicado a promover y fomentar innovaciones tecnológicas y otorgar protección vía patentes. Sin duda, este cambio institucional fue determinante en el desempeño económico de México al dar mayor certidumbre y un marco de mejores incentivos a los actores económicos.

2 En 2006 Venezuela tomó la decisión de salir de esta institución.

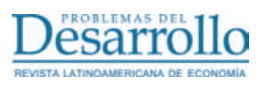

Vol. 39, núm. 154, julio-septiembre / 2008 
Otro aspecto importante fue la creación de la Ley de Metrología y Normalización en 1992 y la creación de los organismos como el Instituto Mexicano de Normalización y Certificación y el Centro Nacional de Metrología, que tiene como objetivo elaborar, revisar, emitir, publicar y cancelar Normas Oficiales Mexicanas, establecer el sistema general de unidades de medida y precisar conceptos fundamentales sobre metrología. Se promovió el uso del sello oficial de garantía en el cual se aplican el mínimo de normas y especificaciones en los productos, a fin de elevar su calidad y beneficiar a los consumidores. El proceso de normalización en México es un hecho fundamental para la actividad exportadora e importadora; un país que quiera insertarse en los mercados internacionales tiene que cumplir con las normas oficiales. En cuanto a los consumidores, su importancia radica en la mayor certidumbre e información que obtienen acerca de los productos que consumen, el país de procedencia e información comercial, hecho importante para la elección económica de los individuos.

Por otro lado, la autonomía del Banco de México con la reforma al artículo 28 constitucional y la creación de Ley del Banco de México en 1993 establecen como objetivo prioritario procurar la estabilidad del poder adquisitivo de la moneda nacional y que las finalidades del banco sean promover el sano desarrollo del sistema financiero y propiciar el buen funcionamiento de los sistemas de pagos, lo que tiene una relevancia fundamental para la estabilidad macroeconómica de México puesto que le quita discrecionalidad a las decisiones de política monetaria.

Estas reformas institucionales son de suma importancia para entender las diversas transformaciones que México experimentó; incluso algunas de ellas ejercieron gran presión en terrenos que no están directamente vinculados con la economía, como el ámbito político. En este sentido, la creación institucional que tiene gran trascendencia en el desarrollo político de México es la promulgación del Código Federal de Instituciones y Procedimientos Electorales en 1990, que establece el Instituto Federal Electoral, cuyo principal objetivo es la preparación, organización y conducción de los procesos electorales.

Aquí es donde podemos ver la parte positiva del cambio institucional: las modificaciones en el marco jurídico que dieron mayor eficiencia y transparencia influyeron en la dinámica de la esfera política. Sin embargo, el sistema político también hubiera requerido de una reforma institucional tan profunda como en el económico, sobre todo en el Estado y aparato gubernamental, así como en las relaciones con los poderes Ejecutivo, Judicial y en general con las fuerzas de la sociedad (véase cuadro 1).

Vol. 39, núm. 154, julio-septiembre / 2008

Desarrollo 


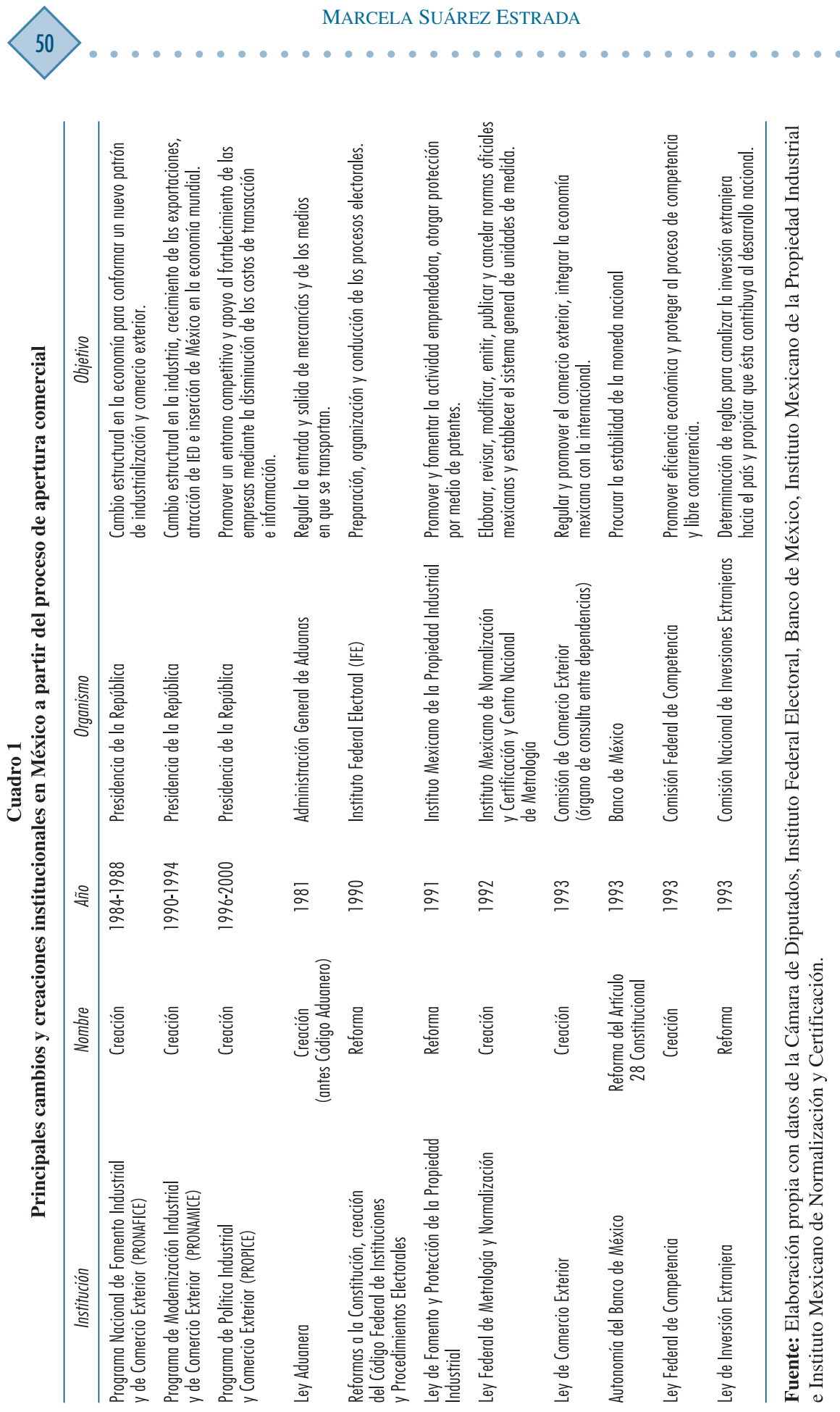

Dessarrollo

Vol. 39, núm. 154, julio-septiembre / 2008 


\section{El desempeño económico en México después de la apertura comercial}

La evolución del comercio exterior mexicano muestra un cambio estructural como resultado de las transformaciones institucionales realizadas, así como de otra serie de factores que se conjuntaron en todo el periodo de análisis.

Gráfica 1

Comercio total de México 1982-2006

(millones de dólares)

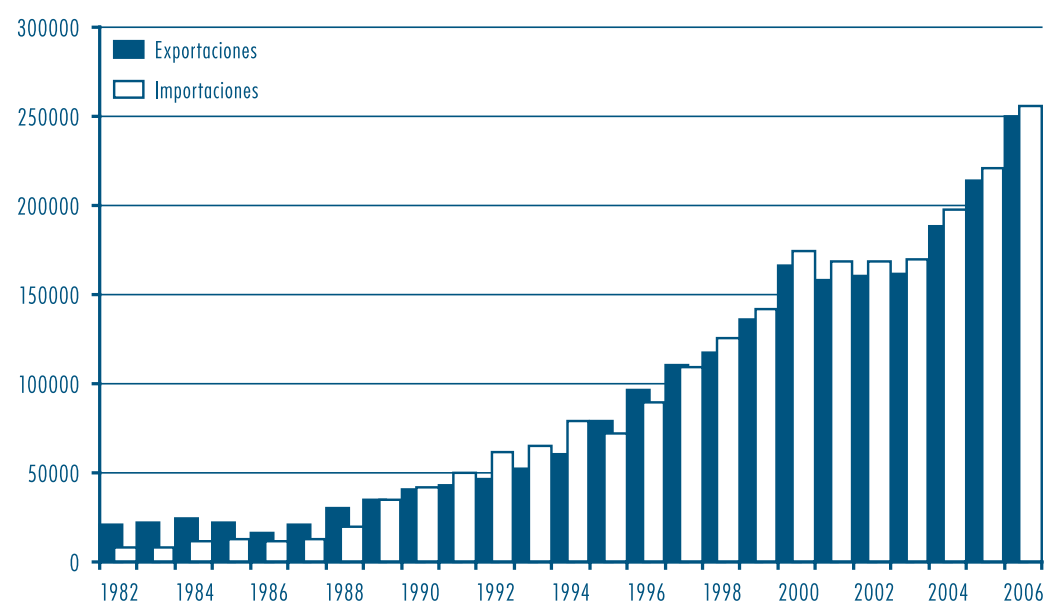

Fuente: Elaboración propia con datos del Banco de México y la Secretaría de Economía.

A principios de la década de los ochenta se empezó a configurar un cambio en el comercio exterior: la estructura de las exportaciones muestra que en 1982 las exportaciones petroleras constituían $68.9 \%$ del total; las manufactureras $25.9 \%$, y las agropecuarias 5.2\%; mientras que para 2006 las exportaciones manufactureras representan $80 \%$; las petroleras $16 \%$ y las exportaciones agropecuarias $2.8 \%$. Sin embargo, en lo que respecta a las importaciones la estructura no ha sufrido cambios tan radicales como la de las exportaciones, pues en 1982 corresponde al sector manufacturero $87.7 \%$, las del sector agropecuario $10.3 \%$ y las de minería y petróleo 2\%; para 2006 las importaciones de bienes intermedios han incrementado su importancia en la estructura total hasta alcanzar $73.6 \%$, bienes de consumo $14.4 \%$ y bienes de capital $12 \%$.

La estructura de las exportaciones dentro del sector manufacturero también muestra un cambio durante 1982-2006, tres ramas disminuyeron considerablemente su partici- 
pación en el total de las exportaciones del sector manufacturero: alimentos y bebidas que contribuían con 20.9\% en 1982 para 2006 disminuyeron a 3.4\%; la rama de química pasó de $24.4 \%$ a $3.2 \%$ y la siderurgia bajó de $14.5 \%$ a 3\% en el mismo periodo. En contraparte, el aumento más destacable fue la rama de productos metálicos, maquinaría y equipo que se incrementó de $26.2 \%$ a $74.2 \%$ de 1982 a 2006. El comportamiento de esta rama se puede explicar por el papel de la IED en el comercio exterior y en particular de las empresas maquiladoras, sobre todo en los subsectores equipo, aparatos eléctricos y electrónicos que contribuyen con $27.7 \%$ de las exportaciones totales del sector manufacturero; industria automotriz con $26.1 \%$, y maquinaría y equipo para industrias diversas con $13.7 \%$. Estos subsectores son los mismos que han mostrado mayor fortaleza en cuanto al proceso de inserción de México en los mercados internacionales.

La cifras de la estructura del comercio exterior muestran que hay concentración en la estructura de las exportaciones en el sector manufacturero en algunas ramas, y en las importaciones en el sector de bienes intermedios, situación que se puede explicar también por el efecto de la inversión en empresas maquiladoras en la composición y concentración del comercio exterior mexicano; así vemos cómo el papel de la IED es determinante para explicar el cambio estructural y la conformación de un nuevo patrón productivo.

Cuadro 2

Cambio estructural en las exportaciones del sector manufacturero (valores en millones de dólares y porcentajes respecto al total)

\begin{tabular}{|c|c|c|c|c|}
\hline \multirow[t]{2}{*}{ Sector } & \multicolumn{2}{|c|}{1982} & \multicolumn{2}{|c|}{2006} \\
\hline & Valor & Porcentaje & Valor & Porcentaje \\
\hline 1. Alimentos y bebidas & 707 & 20.9 & 6,936 & 3.4 \\
\hline 2. Textiles, artículos de vestir, cuero y calzado & 150 & 4.4 & 9,329 & 4.6 \\
\hline 3. Industria de la madera & 52 & 1.5 & 752 & 0.3 \\
\hline 4. Papel & 78 & 2.3 & 1,863 & 0.9 \\
\hline 5. Química & 844 & 24.9 & 6,546 & 3.2 \\
\hline 6. Productos de caucho y plástico & $n d^{*}$ & n.d. & 5,875 & 2.9 \\
\hline 7. Minerales no metálicos & 139 & 4.1 & 2,978 & 1.4 \\
\hline 8. Siderurgia & 490 & 14.5 & 6,264 & 3.0 \\
\hline 9. Minerometalurgia & nd & n.d. & 6,010 & 2.9 \\
\hline 10. Productos metálicos, maquinaria y equipo & 888 & 26.2 & 150,685 & 74.2 \\
\hline equipo-aparatos eléctricos-electrónicos & nd & nd & 56,376 & 27.8 \\
\hline industria automotriz & nd & nd & 53,101 & 26.2 \\
\hline maquinaria y equipo para industrias diversas & nd & nd & 27,811 & 13.7 \\
\hline otros & nd & nd & 13,397 & 6.6 \\
\hline 11. Otras industrias & 35 & 1.1 & 5,628 & 2.7 \\
\hline Total & 3,386 & 100 & 202,865 & 100 \\
\hline
\end{tabular}

* Se encuentran incluidas en el sector química.

Fuente: Elaboración propia con datos de Banco Nacional de Comercio Exterior. 
La historia del intercambio comercial por países muestra que las exportaciones han estado concentradas con EU; para 1982, 58.2\% de las exportaciones tenían como destino ese mercado, le seguían en importancia España, 7.3\%; Japón con 6.9\% y Francia 3.8\%. En 2006 se profundizó la tendencia de concentración de las exportaciones, pues se colocó $85.5 \%$ del total en el mercado estadounidense; otros destinos que destacan son Canadá con $1.6 \%$ y socios históricos como Alemania con $1.3 \%$ y España con $1.3 \%$.

Es importante tener este elemento presente pues la estructura y el comportamiento de los flujos de inversión que México recibe están en parte determinados por la inversión en maquiladoras y el programa PITEX ${ }^{3}$ que tiene como objetivo importar mercancías para su montaje o transformación y posterior exportación. Así los países aprovechan la gama de acuerdos institucionales de México con varios de ellos en el marco de los acuerdos comerciales.

Por todo lo anterior, el aumento del comercio exterior y la explosión de los flujos de IED redefinieron otro patrón de nuevos ejes, zonas y centros geográficos articulados al mercado estadounidense que generaron procesos de reestructuración territorial por medio del despliegue de vínculos interterritoriales y transfronterizos, tales como corredores comerciales y de transporte, al igual que nuevas funciones de centros urbanos.

Debido a lo anterior, las empresas mexicanas se enfrentaron ante un contexto de intensa competencia en el mercado interno debido a la llegada masiva de productos extranjeros con bajos precios y más competitivos; algunas empresas mexicanas arrastraban un rezago productivo y tecnológico que condicionó su capacidad para hacerle frente a esta situación.

Así, se observa que las reformas institucionales también profundizaron la heterogeneidad de la planta productividad nacional y estuvieron asociadas a diferentes capacidades de ajuste y modernización de los sectores y empresas, así como a su capacidad para redefinir sus relaciones comerciales con el exterior. Algunos sectores productivos recurrieron a una estrategia de importación de insumos para ocupar mercados externos, pero sin lograr la modernización suficiente que esa estrategia implica (Casar:1993). Otras empresas se especializaron en alguna parte específica de su proceso productivo, dejando de realizar actividades y sustituyendo producción interna por importaciones.

3 Es importante destacar que para 2006 se unen los programas de IME y PITEX con el decreto al Programa de Industria Manufacturera, Maquiladora y de Servicios de Exportación. 
Además el Estado reformuló su papel en la economía al pasar de ser un actor interventor a uno ausente que sólo creó las reglas del juego para hacer el ambiente más eficiente, pero no desarrolló otro tipo de apoyos necesarios para enfrentar un proceso tan importante, pues se pensaba que la oferta y la demanda generarían el proceso de adaptación de la industria de forma automática; hicieron falta estímulos productivos, financieros, de infraestructura y tecnológicos (Clavijo:1994a; Dussel:1997). En la evolución del comercio exterior también se observa que existe una concentración geográfica en sectores que ha estado determinada y profundizada por el papel de la IED y por la relación comercial con EU. A lo largo del tiempo y en la evolución de los periodos aquí estudiados se observa una agudización en la concentración de ambos fenómenos.

Destaca el papel de las maquilas y el programa PITEX, que han desarrollado un patrón de especialización productivo basado en crecientes importaciones de mercancías para su posterior reexportación, lo que ha tenido algunos efectos negativos en la economía como desequilibrios en la balanza en cuenta corriente, débiles encadenamientos productivos y restricciones macroeconómicas, así como en la configuración en la concentración empresarial, sectorial y geográfica del comercio exterior mexicano.

Así, las ramas del sector manufacturero que están fuertemente vinculadas con las empresas transnacionales, monopolios u oligopolios nacionales, o grandes grupos, han podido responder mejor al proceso de apertura comercial; las ramas tradicionales muestran una contracción de sus actividades, lo que pone en evidencia la falta de especialización y competitividad en algunos sectores productivos nacionales.

Lo anterior ha configurado una polarización económica con un sector dinámico caracterizado por grupos de grandes empresas (en su mayoría) que participan activamente en el comercio exterior y se han visto beneficiadas de la recepción de los flujos de inversión en donde se han llevado a cabo mejoras en cuanto a la organización, formación y tecnología (caso del sector automotor-autopartes y electrónica) (Dussel:1997). Y otro sector rezagado de los beneficios es el compuesto en su mayoría por pequeñas y medianas empresas con débiles encadenamientos productivos, poca participación en los mercados internacionales y limitaciones para hacer frente a la competencia interna debido a la explosión de importaciones derivadas de la apertura comercial.

Se observa que a la creación y transformación institucional del proceso de apertura comercial le ha faltado la coherencia, armonía y fortaleza interna necesarias. La planta productiva del país requería de políticas de apoyo específicas para enfrentar un proceso tan ambicioso como la rápida y profunda apertura comercial. Ante tal situación se desarrolló otro tipo de instituciones y de patrones de interacción para adaptarse a una realidad económica cada vez más compleja.

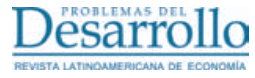

Vol. 39, núm. 154, julio-septiembre / 2008 
Aunque el proceso de apertura comercial era necesario debido al excesivo proteccionismo que limitaba la eficiencia e innovación tecnológica de las empresas, se observan dos fenómenos: 1) que fue un proceso demasiado apresurado y drástico; y 2) que no tuvo como soporte otro tipo de instituciones desde el comienzo que respaldaran a las empresas en un proceso de transformación tan profundo. La problemática se intensificó cuando se creyó que la adaptación de la industria nacional a las nuevas condiciones de competencia interna y externa sería de forma automática, sin tomar en cuenta las necesidades específicas de cada sector, su situación y sus capacidades para hacer frente a un proceso de tal envergadura. Varias compañías tuvieron serias incapacidades para ajustarse a un nuevo entorno de forma satisfactoria, por lo que evolucionan otro tipo de instituciones como la informalidad, la evasión de impuestos, la concentración de actividades económicas en ciertos sectores y la concentración de beneficios.

\section{Comentarios finales}

El proceso de apertura comercial mexicano provocó una serie de transformaciones en el interior de la economía y en la dinámica del desempeño económico. En este trabajo se intentó analizar este complejo fenómeno desde la perspectiva de la teoría institucional que nos brindó los elementos necesarios para entender la importancia de aspectos políticos, geográficos e históricos en un proceso de transformación institucional de tal envergadura como el proceso de apertura comercial en México.

El marco teórico de la teoría institucional nos brindó las categorías analíticas necesarias para abordar un fenómeno económico sin necesidad de desvincularlo de la esfera política, con énfasis en la importancia del Estado y su papel respecto a su gran trascendencia como promotor, coordinador de actividades económicas y proveedor y comunicador de información entre los agentes, así como en cuanto a su papel de creador de instituciones de forma intencional.

Los profundos cambios institucionales de la apertura comercial en México respondieron a la interacción de tres factores: el evolutivo, el accidental y el intencional, aunque en el artículo se ha hecho mayor énfasis en las instituciones formales que han surgido como iniciativa del Estado y se reflexiona acerca de cómo influyeron en la dinámica económica.

La intención de este trabajo no fue establecer relaciones causales precisas respecto al papel de las instituciones en el desempeño económico después de la apertura comercial desde una sola dimensión, sea positiva o negativa. El objetivo fue investigar qué papel jugó la creación y el cambio institucional en la apertura comercial y cuál fue su influencia en el desempeño económico. Se intentó analizar el proceso 
desde una base que permitiera entender que los elementos positivos y negativos en un proceso económico de esta naturaleza no son excluyentes; es decir, la transformación institucional de la apertura comercial en México tiene elementos positivos y negativos que interactúan generando una dinámica propia que ayudan a explicar de forma más integral el desarrollo institucional y el desempeño económico.

En el periodo 1982-1988 se sentaron las bases para la internacionalización de la economía mexicana y se crearon instituciones importantes que estuvieron encaminadas hacia la desregulación de la economía, la apertura comercial y la liberalización de flujos de IED. Las bases institucionales para instaurar el proceso de apertura comercial se realizaron con el PRONAFICE, PRONAMICE, PROPICE y con la Ley de General de Impuestos de Importación y Exportación que modificaron toda la estructura institucional arancelaria y que destruyó el esquema proteccionista de los 40 años anteriores. En materia de IED destaca la importancia del Decreto para el Fomento de la IME y el Decreto PITEX que fomentaron la recepción de flujos de IED en actividades productivas, sobre todo en el centro-norte del país. En este periodo se establecieron los cimientos del cambio estructural y apertura comercial, en un contexto de fuerte inestabilidad económica.

En el siguiente periodo, 1988-1994, se profundizó la creación y transformación de instituciones para mejorar la eficiencia del mercado con la Ley Federal de Competencia, la Ley de Fomento y Protección de la Propiedad Industrial y la Ley de Metrología y Normalización que dieron certidumbre ante el establecimiento de reglas más claras para los agentes y para el intercambio económico. Otras instituciones crearon incentivos para fomentar un mayor intercambio económico como fueron los casos de la Ley de Comercio Exterior, la Ley Aduanera, la Ley de Inversión Extranjera, la Ley Federal de Puertos y la Ley de Navegación y Comercio Marítimos. El resultado fue que los flujos de comercio iban en aumento gradualmente con una clara transformación en su estructura, donde el sector manufacturero delineó su importancia e hizo que aumentase el comercio intraindustrial.

En 1994-2000 destacan las medidas institucionales en el ámbito internacional como la entrada en vigor de los TLC, y diferentes acuerdos como los AAE y APPRI. También en esta etapa destacan algunos cambios políticos como la descentralización política y mayor autonomía de los gobiernos estatales, así como una mayor participación de otros partidos políticos en la toma de decisiones. Es quizá el periodo donde se puede observar más claramente en el desempeño económico los resultados de las reformas institucionales, pues se experimenta una explosión de flujos de comercio exterior y de IED.

Todos los cambios institucionales antes señalados influyeron en la creación de una nueva dinámica en el desempeño económico de México, un aumento considera- 
ble de los flujos de comercio exterior y de IED debido al rompimiento del esquema proteccionista, mayor eficiencia en la organización del mercado, reglas más claras para los agentes y una institucionalización de incentivos claros para un mayor intercambio económico.

La redefinición del papel del Estado en la economía a partir del proceso de apertura comercial fue benéfica al no sustituir la actividad de las empresas y no distorsionar las funciones del mercado. El Estado promovió un cambio profundo de instituciones formales para mejorar un ambiente en el que se desarrollarían las empresas; sin embargo, se llevó a cabo un intenso cambio de apertura comercial en condiciones de rezago productivo de la industria nacional, sin apoyo de otros mecanismos institucionales integrales como políticas de apoyo a empresas para su reconversión industrial de financiamiento, productivas, tecnológicas y de infraestructura, lo cual hizo que los cambios institucionales no reflejaran las capacidades reales de las empresas. Esta situación colocó a la planta productiva nacional en dificultades para adaptarse a una nueva realidad, por lo que se fue generando un nuevo patrón de comercio exterior con ciertas características particulares, a saber: 1) aumento del comercio exterior, motivados por flujos de IED en empresas maquiladoras y ensambladoras que utilizan insumos de importación para transformarlos y reexportarlos con bajos encadenamientos productivos con el resto de la economía; 2) incapacidad de algunas empresas nacionales para hacer frente al proceso de apertura comercial, debido al rezago tecnológico, organizativo y falta de mecanismos institucionales que apoyaran un proceso de tal envergadura; y 3) concentración de sectores, regiones y de países de origen y destino de los flujos de comercio exterior.

En suma, el impacto del cambio institucional en México en el proceso de la apertura comercial tuvo dos vertientes en el desempeño económico: un lado positivo en cuanto a una mejor coordinación, eficiencia y certidumbre en el mercado, cambio en los patrones de interacción de los principales agentes, mediante una mayor transparencia en la toma de decisiones por parte del Estado, así como un aumento de flujos de comercio exterior e IED. Sin embargo, debido a la complejidad del proceso institucional de apertura comercial contribuyó a que se experimentara un crecimiento económico modesto, polarización económica, concentración de las actividades comerciales en regiones, países y sectores. Al profundo cambio institucional del proceso de apertura comercial le hizo falta la participación más activa del Estado y también un mayor consenso en cuanto a la coherencia, necesidades y condiciones específicas de la industria nacional y respecto a sus capacidades reales.

Vol. 39, núm. 154, julio-septiembre / 2008

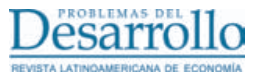




\section{Bibliografía}

Aspe, Pedro, El camino mexicano de la transformación económica, México, FCE, 1993, pp. 133.

Ayala, José, Estado y desarrollo. La formación de la economía mixta mexicana en el siglo $X X$, México, Facultad de Economía, México, UNAM, 1996, pp. 167.

Bortis, Heinrich, Institutions, behavior and economic theory. A contribution to classicalkeynesian political economy, Cambridge, Cambridge University Press, 1997, pp. 435.

Bulmer, Thomas, La historia económica de América Latina desde la Independencia, México, FCE, 1994, pp. 563.

Burlamaqui, Leonardo et al., Institutions and the Role of the State, Cheltenham, Edwar Eldgar, 2000, pp. 293.

Camp, Roderic Ai., Politics in Mexico the Democratic Transformation, Oxford, Oxford University Press, 2003, pp. 294.

, Los empresarios y la política en México. Una visión contemporánea, México, FCE, 1990, pp. 290.

Cárdenas, Enrique, La política económica en México, 1950-1994, México, FCE, 1996, pp. 235.

Casar, José, Comercio exterior, política comercial y macroeconomía: México en los Ochenta, Montevideo, ALADI, 1993, pp.87.

Chang, Ha Joon, Retirar la escalera. La estrategia del desarrollo en perspectiva histórica, Madrid, Catarata, 2004, pp. 247.

, El papel del Estado en el cambio económico, México, Ariel, 1996, pp. 211.

Clavijo, Fernando (comp.), "Reformas Económicas en México 1982-1999", en El Trimestre Económico, núm. 92, México, FCE, 2000, pp. 584

et al. (comp.), "La Industria Mexicana en el Mercado Mundial. Elementos para una Política Industrial", en El Trimestre Económico, vol. I y II, núm. 80, México, FCE, 1994a, pp.489.

et al. La Política Industrial en México, México, COLMEX, 1994b, pp.234.

Coase, Ronald, "The Nature of the Firm", en Economica, vol. 4, núm. 16, Londres, New Series, 1937, pp. 386- 405.

Cordera, Rolando, La globalización en México: opciones y contradicciones, México, UNAM-FE, 2006, pp.327.
Domínguez, Lilia y Flor Brown, "Inversión Extranjera Directa y el Efecto Spillover ante el TLCAN”, en Mónica Grambill, Diez años del TLCAN en México, México, UNAM-CISAN, 2006, pp.157-191.

Dussel, Enrique, La economía de la polarización. Teoría y evolución del cambio estructural de las manufacturas mexicanas, México, Jus, 1997, pp. 323.

Gambrill, Mónica. (ed.), Diez años del TLCAN en México, México, UNAM-CISAN, 2006 pp. 502.

Gilpin, Robert, Global Political Economy. Understanding the International Economic Order, Princeton, Princeton University Press, 2001, pp. 423.

Goodin E. Rodin, Teoría del diseño insititucional, Madrid, GEDISA, 2003 pp.345.

Hayek, Friedrich A., El orden sensorial. Los fundamentos de la psicología teórica. Madrid, Unión Editorial, 2004[1952], pp. 365.

La fatal arrogancia: los errores del socialismo, Madrid, Unión Editorial, 1990 pp. 256.

Hodgson, M. Geoffrey, "What are Institutions?", Journal of Economic Issues, vol. XL, núm. 1, marzo de 2006, pp. 26.

Economics and Institutions. A Manifesto for a Modern Institutional Economics, Cambridge, Polity Press, 1988, pp. 365.

Katz, M. Isaac, La apertura comercial y su impacto regional sobre la economía mexicana, México, ITAM, 1998, pp.139.

Knight, H. Frank. Riesgo, incertidumbre y beneficio, Madrid, Aguilar, 1947 [1921]), pp.342.

Knight, Jack, Institutions and Social Conflict, Cambridge, Cambridge University Press, 1992, pp. 231.

Laos, Enrique y Jorge Velázquez, Globalización, desigualdad y pobreza. Lecciones de la experiencia mexicana, México, UAMPlaza y Valdés, 2003, pp. 217.

Loasby, Brian, Knowledge, Institutions and Evolutions in Economics, Londres, Routledge, 1999, pp. 159.

Lustig, Nora, México. Hacia la reconstrucción de una economía, México, FCE-COLMEX, 1994, pp. 307.

Moreno, Juan Carlos y Jaime Ross, "México y las reformas del mercado desde una pers-

Vol. 39, núm. 154, julio-septiembre / 2008 
pectiva histórica", en Revista de la CEPAL, núm. 84, Santiago de Chile, diciembre de 2004, pp. 35-57.

Nelson, Richard y Sidney Winter, An evolutionary theory of economic change, Cambridge, Belknap Press, 1982, pp. 437.

North, Douglas, Instituciones, cambio institucional y desempeño económico, México, FCE, 1993a, pp. 190

North, Douglas, Understanding the Process of Economic Change, New Jersey, Princeton University Press, 2005, pp. 187.

Polanyi, Karl, La gran transformación. Los orígenes políticos y económicos de nuestro tiempo, México, FCE, 2003 [1957], pp. 399.

Rueda, Isabel, Las micro, pequeña y mediana empresas en México en los años noventa, México, UNAM, Instituto de Investigaciones Económicas, 2001, pp. 78.
Shackle, George, Epistémica y economía: crítica de las doctrinas económicas, México, FCE, 1976, pp. 528.

Simon, Herbert, "Bounded Rationality and Organizacional Learning", Reflections, núm. 2, vol. 1, 1991, p. 17-27.

Thelen, Kathleen, Structuring Politics: Historical Institutionalism in comparative politics, Cambridge, Cambridge University Press, 1992 , pp. 304.

Vanberg, Viktor, Racionalidad y reglas. Ensayos sobre teoría económica de la Constitución, Barcelona, Gedisa, 1999, pp. 283.

Williamson, Oliver E., "Transaction Cost Economics: How It Works; Where It Is Headed", Economist 146, núm. 1, 1998, pp. 23-58. 


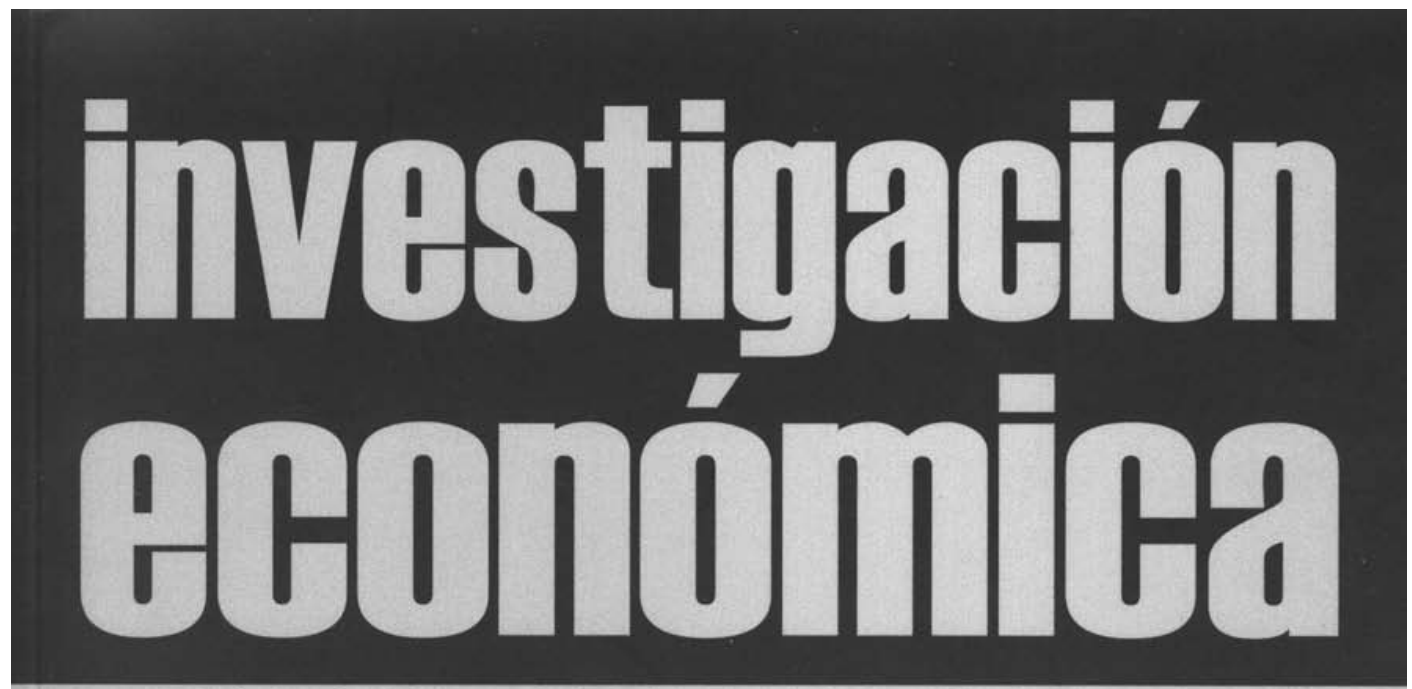

revista de la facultad de economía de la universidad nacional autónoma de méxico

vol. LXVII, núm. 264, abril-junio de 2008

José Alberto Godínez Placencia y Noé Arón Fuentes FLORES, Las condiciones económicas para operar un mercado de futuros de maíz blanco en México

Pu Chen, Gang Gong, Armon Rezai and Willi Semmler, Productivity Shocks in the Short and Long- Run: An Intertemporal Model and Estimation

Fabián Amico, Argentina: diferencias entre el actual modelo de dólar alto y la convertibilidad

Julio G. Andújar-Scheker, The Political Economy of Policy Reform: The Case of the Dominican Republic

Dmitri FujiI y Curtis Huffman, Los programas de estímulos fiscales en México, 2001-2005 